Review Article

\title{
Neurological Components in Coronavirus Induced Disease: A Review of the Literature Related to SARS, MERS, and COVID-19
}

\author{
J. A. Zegarra-Valdivia $\left(\mathbb{D},{ }^{1}\right.$ B. N. Chino-Vilca, ${ }^{2}$ T. Tairo-Cerron, ${ }^{3,4}$ V. Munive, ${ }^{5}$ \\ C. Lastarria-Perez, ${ }^{6}$ and R. J. Ames-Guerrero ${ }^{7}$ \\ ${ }^{1}$ Universidad Nacional de San Agustín de Arequipa, Peru \\ ${ }^{2}$ Center of Biomedical Technology, Laboratory of Cognitive and Computational Neuroscience, Madrid, Spain \\ ${ }^{3}$ Department of Nuclear Medicine, National Institute of Neoplastic Diseases, Lima, Peru \\ ${ }^{4}$ Universidad Peruana Cayetano Heredia (UPCH), Lima, Peru \\ ${ }^{5}$ Psychiatry Department, University of California, San Diego, CA, USA \\ ${ }^{6}$ Neurology Department, Clinic Vallesur AUNA, Arequipa, Peru \\ ${ }^{7}$ Universidad Católica de Santa María, Arequipa, Peru
}

Correspondence should be addressed to J. A. Zegarra-Valdivia; adrianzegarra13@gmail.com

Received 13 May 2020; Revised 6 June 2020; Accepted 8 June 2020; Published 18 September 2020

Academic Editor: Herbert Brok

Copyright (C) 2020 J. A. Zegarra-Valdivia et al. This is an open access article distributed under the Creative Commons Attribution License, which permits unrestricted use, distribution, and reproduction in any medium, provided the original work is properly cited.

\begin{abstract}
Background. COVID-19 has been declared the pandemic of the 21 st century, causing more than 45,000 deaths worldwide. The abrupt release of SARS-CoV-2 demonstrated the potential infection, morbidity, and lethality of zoonotic viruses and humanto-human transmission. Fever, cough, and fatigue are reported as the most common symptoms of the disease, including acute respiratory distress syndrome, and also signs of severe illness, such as shock, acute cardiac injury, and renal lesions, are described. Considering the previous works related to human coronavirus and other zoonotic infections, it has been demonstrated that the neuroinvasive propensity is a common characteristic of coronaviruses, especially in SARS-CoV and MERS$\mathrm{CoV}$. Objective. In the present review, we analyzed the potential neurological components involved in coronavirus infections and detailed the neurological syndromes related to COVID-19. We also examined the mechanism of transmission and CNS pathology related to other viruses with similar structures such as SARS-CoV and MERS-CoV. Methods. A comprehensive search of different original articles and clinical, experimental, and review studies was conducted in MEDLINE/PubMed, Scopus, and Web of Science. We selected 92 articles that have been published in journals or preprints according to the search words and the inclusion and exclusion criteria. Results. COVID-19 patients may experience neurological symptoms such as headache, impaired mental status, confusion, dizziness, nausea and vomiting, anosmia/hyposmia, and dysgeusia/hypogeusia as initial symptoms, with more severe manifestations such as seizures or coma later on. The neurological signs shown are clinical symptoms similar to those reported for SARS-CoV and MERS-CoV. Given that both SARS-CoV and MERS-CoV have similar structures, these viruses may share comparable neurological symptoms and similar progression. Coronaviruses are linked to central nervous system dysfunction, and they are also reported as the probable cause of multiple sclerosis, encephalitis, and meningitis.
\end{abstract}

\section{Introduction}

Difficult days are being witnessed as the COVID-19 pandemic continues to evolve, generating uncertainty and stress throughout the world. The emergence of infectious diseases throughout the history has been the cause of suffering for many human groups, in addition to economic instability and disruption of daily life [1]. Considering that COVID-19 is the new pandemic of the 21st century $[2,3]$, research has increased exponentially in recent months.

Coronaviruses were initially identified in animals, causing different diseases in the respiratory system, 
gastrointestinal system, and central nervous system (CNS) [4]. In the last 18 years, various studies and clinical reports concerning epidemics caused by coronavirus with a substantial impact on human health, especially in Asiatic and Middle East countries, have been reported. These animal-tohuman transmission (zoonotic transmission) and then human-to-human transmission were initially described in Guangdong, China, with the outbreak of the severe respiratory syndrome named "SARS-CoV" [5], which infected 8098 individuals with a mortality rate of $9 \%$, across 26 countries in the world [5]. The subsequent appearance, 10 years later, of the Middle East respiratory syndrome (MERS$\mathrm{CoV}$ ) in Saudi Arabia [6] raised a global alarm about the possible impact on the healthcare system. Similar to SARS$\mathrm{CoV}$, patients suffered from pneumonia, followed by severe acute respiratory syndrome and kidney failure $[5,7]$.

Recently, a highly contagious pandemic has emerged, challenging the healthcare system of governments around the world. This severe acute respiratory syndrome, coronavirus 2 (SARS-CoV-2), was first reported in Wuhan, China, at the start of December and started spreading rapidly around the world, generating COVID-19. The transmission rate of SARS-CoV-2 is higher than that of SARS-CoV [5], and this virus rapidly spread across China and 200 countries around the world, becoming the third epidemic caused by coronavirus in the 21st century [8]. SARS-CoV-2 causes severe respiratory illness similar to fatal coronavirus infections caused by SARS-CoV and MERS-CoV [9].

SARS-CoV-2 infection produces a wide range of clinical symptoms from mild/moderate fever, cough, shortness of breath, and fatigue to more severe pneumonia and cardiorespiratory failure $[10,11]$. Nonetheless, a group of patients present with nontypical symptoms like headache, conjunctivitis, diarrhea, vomiting, sputum, hemoptysis [11], anorexia [12], hyposmia/anosmia [13], and dysgeusia [14].

These symptoms may reflect the different initial niches and progression of the viral infection. Nevertheless, it is still not clear if the virus was limited to the upper respiratory tract. Since the main targets of SARS-CoV-2 are the lungs, early epidemiological reports do not mention alterations in the CNS $[13,15]$, and thus, its potential for opportunistic infection of the central nervous system has been underestimated [16].

Considering the previous description of neurological symptoms after the virus infection by coronaviruses (SARS$\mathrm{CoV}$ and MERS-CoV) and the recent limited descriptions of clinical cases with SARS-CoV-2, this review aims to provide a summary and critical analysis of early findings on neurological symptoms and provide meaningful information for future research related to neurological disorders/syndromes by SARS-CoV-2, as well as support decision-making on strategies to handle this public health emergency.

\section{Methods}

An exhaustive search of different original articles and clinical, experimental, and review studies was performed in MEDLINE/PubMed, Scopus, and Web of Science, with the search words "coronavirus" or "SARS-CoV" or "MERS" or
"COVID-19" or "SARS-CoV-2" and "neurological syndrome" or "central nervous system" or "brain" or "brain infection" or "neurological disorder" (see Appendix for word combinations).

The studies were selected based on their relevance analyzing the possible neurological syndrome related to COVID-19. These articles have been published in magazines or in preprints. We found 92 articles that were organized according to the search words. The references of these selected articles were also scanned for additional studies related to human coronaviruses and CNS infection. A flowchart of the search is shown in Figure 1.

As part of the selection, the following criteria were considered: extensive description of clinical cases, central nervous system infection, and neurological syndrome and studies conducted in animal models or human patients diagnosed with coronavirus. Additionally, a brief review of COVID-19 is performed, and we then explored its relationship with the CNS.

2.1. Coronaviruses and COVID-19: An Overview. Human coronaviruses are usually divided into Alphacoronavirus and Betacoronavirus, the majority of them causing common cold in humans $[4,17,18]$ including $\mathrm{HCoV}-229 \mathrm{E}, \mathrm{HCoV}-\mathrm{OC} 43$, HCoVHKU1, HCoV-NL63, SARS-CoV, and MERS-CoV [19-22]. While, in some cases, opportunistic human coronaviruses may infect the CNS [23,24], and their mechanisms of infection are not widely understood [25]. Nonetheless, the abrupt onset of SARS-CoV, MERS-CoV, and SARS-CoV-2 demonstrated the potential infection, morbidity, and lethality of zoonotic viruses and human-to-human transmission, following respiratory, enteric, and CNS infections [26].

SARS-CoV first appeared in 2002, and it has caused more than 8000 cases of infection, leading to more than 750 deaths in China, Canada, Hong Kong, Vietnam, Singapore, Ireland, Germany, and EEUU $[27,28]$. On the other hand, the MERS-CoV outbreak occurred in Saudi Arabia and affected 27 countries, and 2,000 people were affected by the disease [29]. Currently, SARS-CoV-2 has spread to about 200 countries, and the WHO has reported more than $5,19,000$ cases and 23,000 deaths. These coronaviruses have the potential to cause more severe disease among vulnerable people, such as the elderly or people with chronic debilitating diseases. It is important to note, however, that in the case of SARS-CoV-2, transmission and COVID-19 have also been reported in pregnancy, newborns, infants [30], and young adults.

\subsection{Comparison of Characteristics of COVID-19 with SARS} and MERS. Coronaviruses have the largest genome among the RNA viruses, with a nonsegmented $30 \mathrm{~kb}$ positive-singlestranded polyadenylated RNA possessing 4 or 5 genes encoding structural proteins ( $\mathrm{S}, \mathrm{E}, \mathrm{M}, \mathrm{N}$, and $\mathrm{HE}$ ) and several genes encoding nonstructural proteins [31]. The most prominent feature of coronaviruses is the club-shaped spike projections emanating from the surface of the virions. The spike proteins are believed to be a major determinant of 


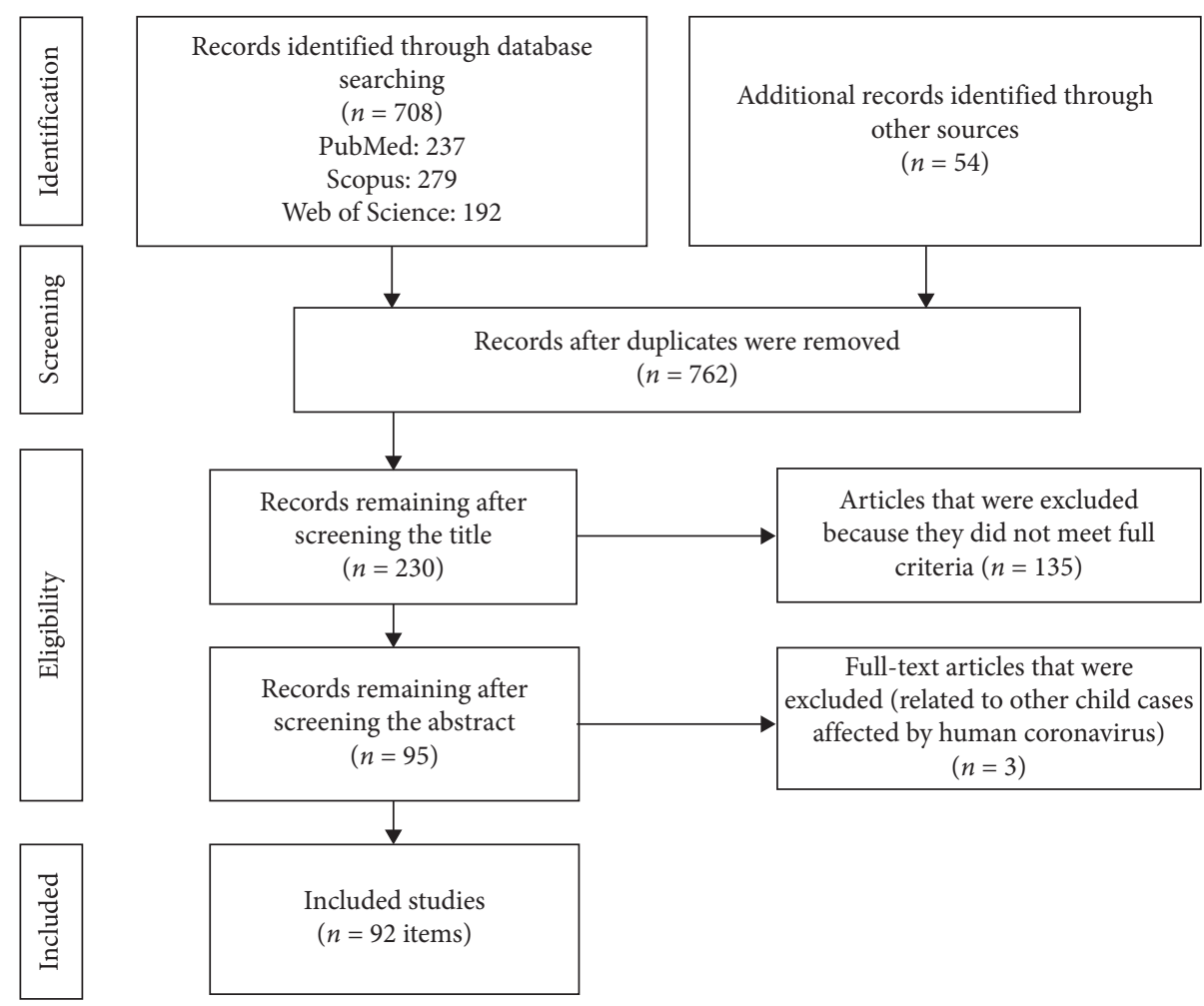

Figure 1: PRISMA flow diagram for the scoping review process.

the pathogenic phenotype [32], and these spikes are a defining feature of the virions and give them the appearance of a solar corona; four coronavirus genera $(\alpha, \beta, \gamma$, and $\delta)$ have been identified so far [18].

Coronaviruses attach to a specific cell surface receptor and then enter the cell by fusion at the plasma membrane or after endocytosis, producing high replication of their genomic RNA [18]. These virions egress from exocytosis after vesicular transport to the cell membrane or cell membrane rupture. The human host may transmit the virions by direct transmission of respiratory secretions like nose drops and saliva. $[17,26,33]$, but other transmission routes are also possible, such as contact with infected objects, aerosol transmission, human feces [26], and others probably not tears [34]; nonetheless, niche viral infection may be possible.

Table 1 describes the main biological characteristics of the new SARS-CoV-2 coronavirus, the severe acute respiratory syndrome coronavirus (SARS-CoV), and the Middle East respiratory syndrome coronavirus (MERS-CoV).

\subsection{Possible Mechanism of Nervous System Infection by} Coronaviruses. Different coronaviruses can outwit the immune response and infect extrarespiratory organs, including the CNS $[16,48]$. Its presence in the brain tissue demonstrates the neuroinvasive and opportunistic capacity of these pathogens $[49,50]$. Autopsy studies have demonstrated by in situ hybridization that coronaviruses can infect the brain, detecting viral particles $[51,52]$.

Furthermore, experimental studies display that coronaviruses infect the mice brain transnasally, and it seems that the infection invades the peripheral nerve terminals and then gains access to the CNS by trans-synapse route or skips the synapse retrograde from infected tissues $[16,53]$, generating behavioral and cognitive impairment [49].

In patients affected with SARS- CoV, the dissemination in the systemic circulation understandably allows it to pass into the cerebral circulation. One of the factors which may facilitate the interaction of the virus spike protein with the ACE2 receptor at the endothelial could be the slow blood movement within the microcirculation. Another proposed mechanism could be the movement of the virus via the cribriform plate close to the olfactory bulb, potentially allowing brain invasion [47].

Furthermore, the haematogenic or lymphatic route may be possible [54]. By these two mechanisms, coronaviruses possess neuroinvasive and neurotropic properties; initially, they can infect the endothelial cells of the blood-brain barrier (BBB), white blood cells, glial cells, or even neurons inducing neurodegeneration and death $[55,56]$. In that way, the coronaviruses contribute to an overactivation of the immune system, triggering or exacerbating the neurological symptoms [49]. There is evidence that these viral infections are possible etiological agents of demyelinating disease [57] or encephalopathy [58-60], although they underlie other brain pathologies.

Neurologic manifestations associated with SARS coronavirus infections include axonopathic polyneuropathy, myopathy, and ischemic stroke [18]. Other studies report dysphoria, vomiting, and deliria [61] and in advance stages, seizures [62]. Brain infection by MERS-CoV has shown a variety of neurologic manifestations such as ataxia, motor 
TABLE 1: Comparison chart of MERS with SARS and COVID-19.

\begin{tabular}{|c|c|c|c|}
\hline Disease & $\begin{array}{l}\text { MERS: Middle East respiratory } \\
\text { svndrome coronavirus }\end{array}$ & $\begin{array}{l}\text { SARS: severe acute } \\
\text { respiratory syndrome } \\
\text { coronavirus }\end{array}$ & $\begin{array}{l}\text { COVID-19: corona virus } \\
\text { disease } 2019\end{array}$ \\
\hline $\begin{array}{r}\text { Virus type [31, 35-37] } \\
\text { Order } \\
\text { Family } \\
\text { Subfamily } \\
\text { Genus }\end{array}$ & MERS-CoV & $\begin{array}{c}\text { SARS-CoV } \\
\text { Nidovirales } \\
\text { Coronaviridae } \\
\text { Orthocoronavirinae } \\
\text { Betacoronavirus }\end{array}$ & SARS-CoV2 \\
\hline
\end{tabular}

Subgenre C
(i) $\sim 85 \%$ to bat (MERSr-CoV)

Nucleotide identity (genomic) $^{*}[25,38]$

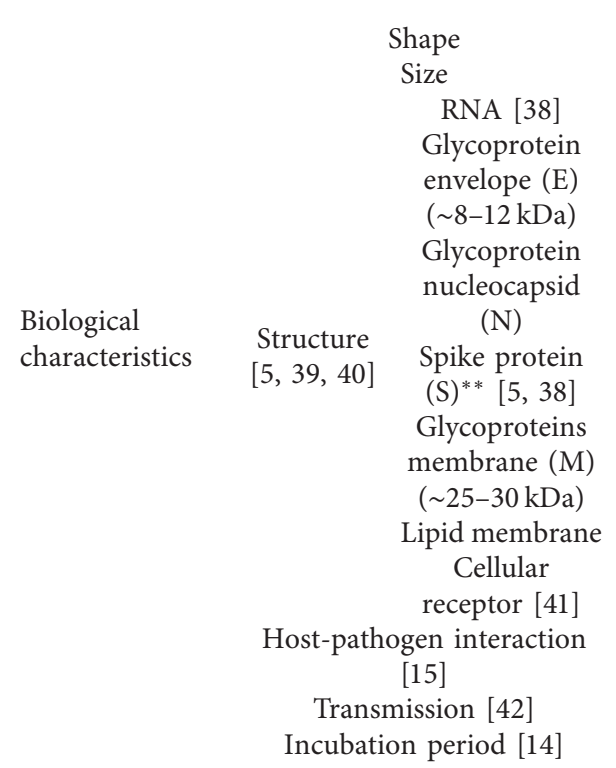

Organ affected $[35,43]$

Immunological response [44]

(ii) $>99 \%$ to camel (MERSr-

CoV)

(iii) $45-65 \%$ the $\mathrm{S}$ protein between bat (MERSr-CoV), human, and camel (MERSr$\mathrm{CoV})$

1270 aminoacids

2-10 days

Unciliated bronchial epithelial cells and type II pneumocytes, epithelial cells in the kidney, and neurological system

Speed of spread [45] Recruitment of immune cells [46]

Low

Dendritic cells, macrophages, and $\mathrm{T}$ cells proinflammatory cytokines
Rounded or elliptical, often pleomorphic $65-125 \mathrm{~nm}$ in diameter

Positive-sense RNA genome ranging from 26 to 32 kilobase in length

Interfered with host immune response or unknown function

1255 aminoacids

1273 aminoacids

Responsible for the transmembrane transport of nutrients, the bud release, and the formation of envelope

\begin{tabular}{|c|c|c|}
\hline Yes & Yes & Yes \\
\hline $\begin{array}{c}\text { DPP4 or CD26 (dipeptidyl } \\
\text { peptidase } 4)\end{array}$ & ACE2 & $\mathrm{ACE} 2 * * *$ \\
\hline Bat $\longrightarrow$ camel $\longrightarrow$ human & Bat $\longrightarrow$ civet cat $\longrightarrow$ human & $\begin{array}{c}\text { Bat } \longrightarrow \text { snake or } \\
\text { pangolin } \longrightarrow \text { human }\end{array}$ \\
\hline
\end{tabular}
2-14 days

Lymphocytes, monocytes and lymphoid tissues, small intestine, liver, prostate,

ciliated bronchial epithelial cells and type II pneumocytes, intestinal mucosa, epithelium of renal distal tubules, tissue-

resident macrophages, and neurons in the brain Moderate

Monocyte/macrophages, dendritic cells

IL-1, IL-6, IL-12, interferon

TNF- $\alpha$, IL-6, CXCL-10, CCL-2, $\quad \gamma$ (IFN- $\gamma$ ), transforming CCL-3, CCL-5, and IL-8 growth factor- $\beta$, CCL2, CXCL9, CXCL10, and IL-8 and chemokines [43]

Evades the response immune
Lung alveolar epithelial cells and enterocytes of small intestine remarkably, the kidneys and liver

\section{High}

Monocyte/macrophages, neutrophils

IL-8, IL-9, IL-10, basic FGF, GCSF, GMCSF, IFN $\gamma$, IP10, MCP1, MIP1A,

MIP1B, PDGF, TNF- $\alpha$, and factor

Delayed innate immune response
IL- $1 \beta$, IL-1R $\alpha$, IL-6, IL-7, vascular endothelial growth
Delayed development of the innate and adaptive immune response and prolonged virus clearance

\footnotetext{
${ }^{\circ}$ Images adapted from Cui et al. 2018 [47]. *The genome comprises the $5^{\prime}$-untranslated region (5'-UTR), open reading frame (ORF), 1a/b encoding nonstructural proteins (NSPs) for replication, and structural proteins including S, E, M, and N and accessory proteins (studies have indicated notable variations in SARS-CoV and SARS-CoV2 such as the absence of 8 a protein and fluctuation in the number of amino acids in $8 \mathrm{~b}$ and $3 \mathrm{c}$ protein in SARS-CoV2). ${ }^{* *}$ Envelope spike protein $(\mathrm{S})$ is functionally divided into the $\mathrm{S} 1$ domain, responsible for receptor binding, and the S2 domain, responsible for cell membrane fusion. ${ }^{* * *}$ ACE2: human angiotensin-converting enzyme 2. SARS-CoV2 has 14 binding residues that interact with the ACE2 receptor and is 10- to 20-folds higher than that of SARS-CoV.
} 
deficits, and altered mental state from confusion to coma [63] or headache, nausea, and vomiting [54]. The rapid infection and replication of MERS-CoV in human dendritic cells, macrophages, and primary $\mathrm{T}$ cells aggravate the infection and production of proinflammatory cytokine/chemokine [64], worsening the response and inducing massive apoptosis [65].

Perhaps, the neuroinvasive potential by SARS-CoV-2 needs some more elucidation. Taking the previous work with human coronavirus and other zoonotic infections as reference, neuroinvasive propensity has been demonstrated as a common feature of coronaviruses [53, 66], especially between SARS-CoV and SARS-CoV-2 [67]. Other studies show that the human brain cell lines are capable of or have been infected by coronaviruses [68], including astrocytoma, neuroblastoma, and oligodendrocytes cell lines [61].

Recently, the presence of the ACE2 receptor has been demonstrated on glial cells and neurons. The COVID-19 virus uses a protein $\mathrm{S} 1$ that interacts with the ACE2 receptor and allows the binding of the virions to the target cell membrane [47]. Even the peak proteins of the three coronaviruses are similar, not identical, which explains the greater affinity of the COVID-19 peak protein with the human ACE2 receptor.

\subsection{Neurological Syndrome by Coronaviruses. SARS-CoV} and MERS-CoV are zoonotic diseases that can infect both humans and animals. Both viruses have a very similar structure. Infection by these viruses in humans produce typical clinical characteristics such as fever, myalgia, cough, and dyspnea, which typically proceed to shortness of breath and pneumonia. Other clinical characteristics consider nontypical symptoms like diarrhea, anorexia, anosmia, and hyposmia. Furthermore, it seems that SARS, MERS, and COVID-19 have similar incubation periods [69].

Different studies point out that, before and after virus confirmation by reverse transcriptase polymerase chain reaction in the respiratory sample, neurologic symptoms would be present and may have been underdiagnosed previously. These symptoms included dizziness, headache, vomiting, and confusion. It may also include weakness in the upper and lower limbs, altered reflexes, or ataxia. More severe symptoms may range from generalized tonic-clonic seizures, loss of consciousness, coma, and death. A review of different studies is shown in Table 2.

Given the progression of those symptoms, changes in the immune response were manifested [81], especially macrophage activation, increased lymphocytes, and expression of chemokine receptors on activated T cells. [58], which are usually analyzed in a blood sample or CFS, and also cytopathic effects are observed. Neuroimaging methods such as tomography and MRI showed inconclusive results, with some patients showing normal values and others displaying hypodensity and hyperintensity in different areas of the brain, including stroke [62].

In addition, the human respiratory epithelium is highly susceptible to SARS-CoV and MERS-CoV which may support productive viral replication, as shown in the first case. Most patients had three or more damaged organs or systems after exposure to SARS-CoV-2 [9], and it is possible to define, additionally, the first symptoms associated with the infection of the CNS.

2.5. Clinical Symptoms in Neurological COVID-19 Patients. At present, there are some reports referring to the neurological symptoms of COVID-19 patients. These studies indicate that neurological signs, such as headache, nausea, and vomiting, are the initial symptoms. Some other documents indicate a diminished sense of smell, diminished sensation of taste, or even anosmia (Table 2). The reported neurologic signs are clinical symptoms similar to those informed in SARS-CoV and MERS-CoV. Considering that SARS-CoV and MERS-CoV have a similar structure and as several reports point out, comparable neurological symptoms are notable which indicates that the progression would be similar. Different coronaviruses are linked to CNS dysfunction, and they are reported as the probable cause of multiple sclerosis, encephalitis, and meningitis [82-84]. Hence, viruses could be another potential source of brain dysfunction even in the absence of a lung with low respiratory tract infection.

Well-defined mechanisms of transmission between the lower and upper respiratory tracts of the CNS remain unknown. From other studies on coronaviruses, however, we could suggest that transmission begins even in the upper or lower respiratory tract, forming different viral niches with the possibility of altering the respiratory epithelium, reaching the bloodstream or lymph and spreading to the CNS $[49,85]$, and crossing the BBB and infecting the brain neurons such as glial cells or neurons, for example [84], the latter being more susceptible to infection by coronaviruses [46] (Figure 2). Another variant of infection would be by axonal transport, retrograde transmission from the respiratory organs, or even the enteric nervous system as do other coronaviruses [85-89].

Examination of the data suggests that coronavirus may reach the CNS and induce the disease in the short term, but it is not known whether it can persist in resident human CNS cells and may become a factor or cofactor in neuropathogenesis associated with a long-term neurological syndrome or sequel in vulnerable populations with other comorbidities, children [90] or elderly populations.

\section{Discussion}

The aim of this review was to elucidate the possible neurological component by coronavirus infections, specifically SARS-CoV, MERS-CoV, and SARS-CoV-2. Considering the recent descriptions of neurological symptoms after SARSCoV-2 infection, we reviewed more than 90 papers in the last 20 years related to coronavirus brain infection and included different human, clinic, and experimental studies. We detail a neurologic syndrome related to COVID-19 and review the transmission mechanism and CNS pathology related to another virus with the similar structure (SARS/MERS).

Despite many other coronaviruses being discovered before SARS-CoV outbreak [91], different researches took 


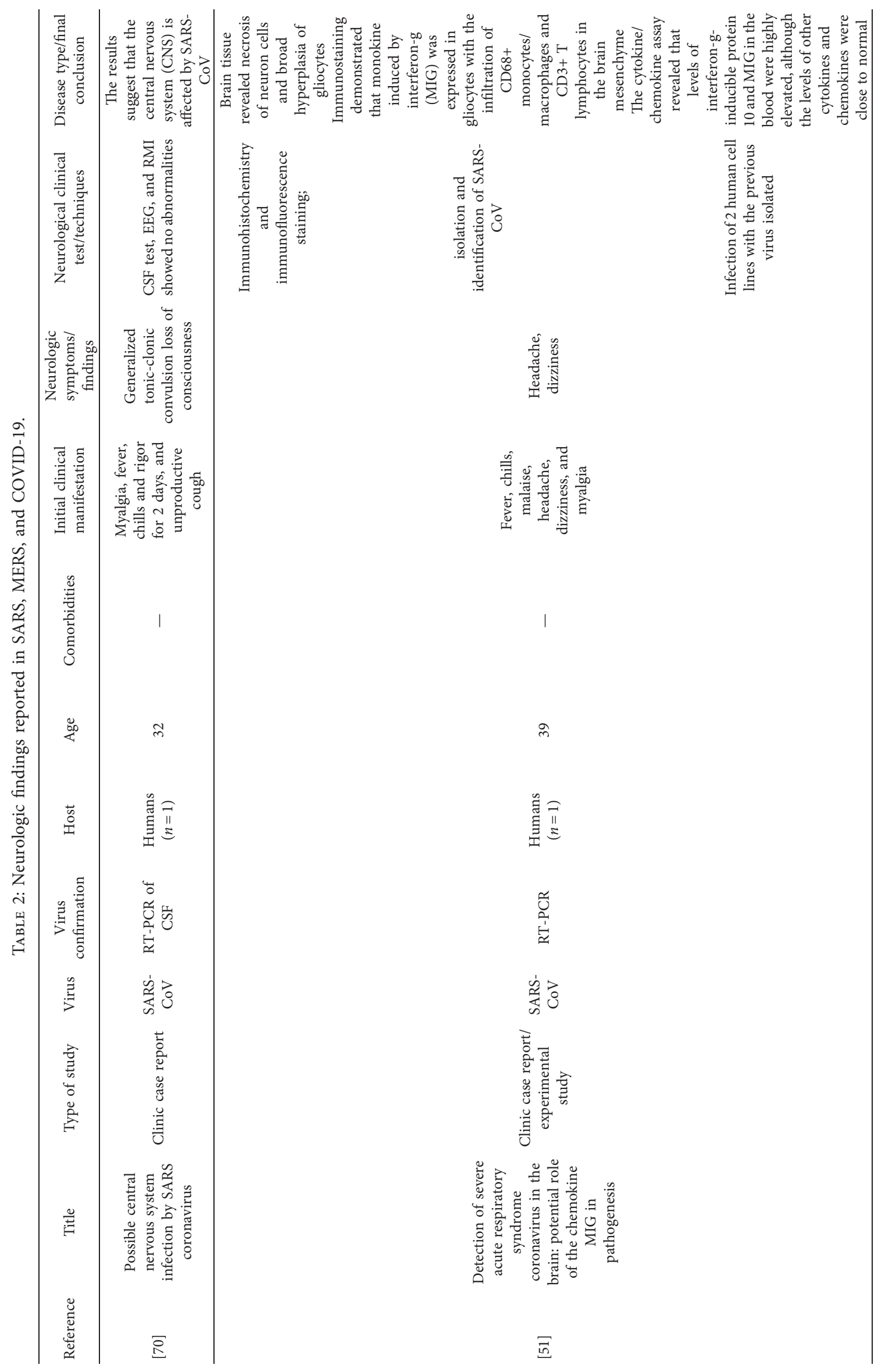




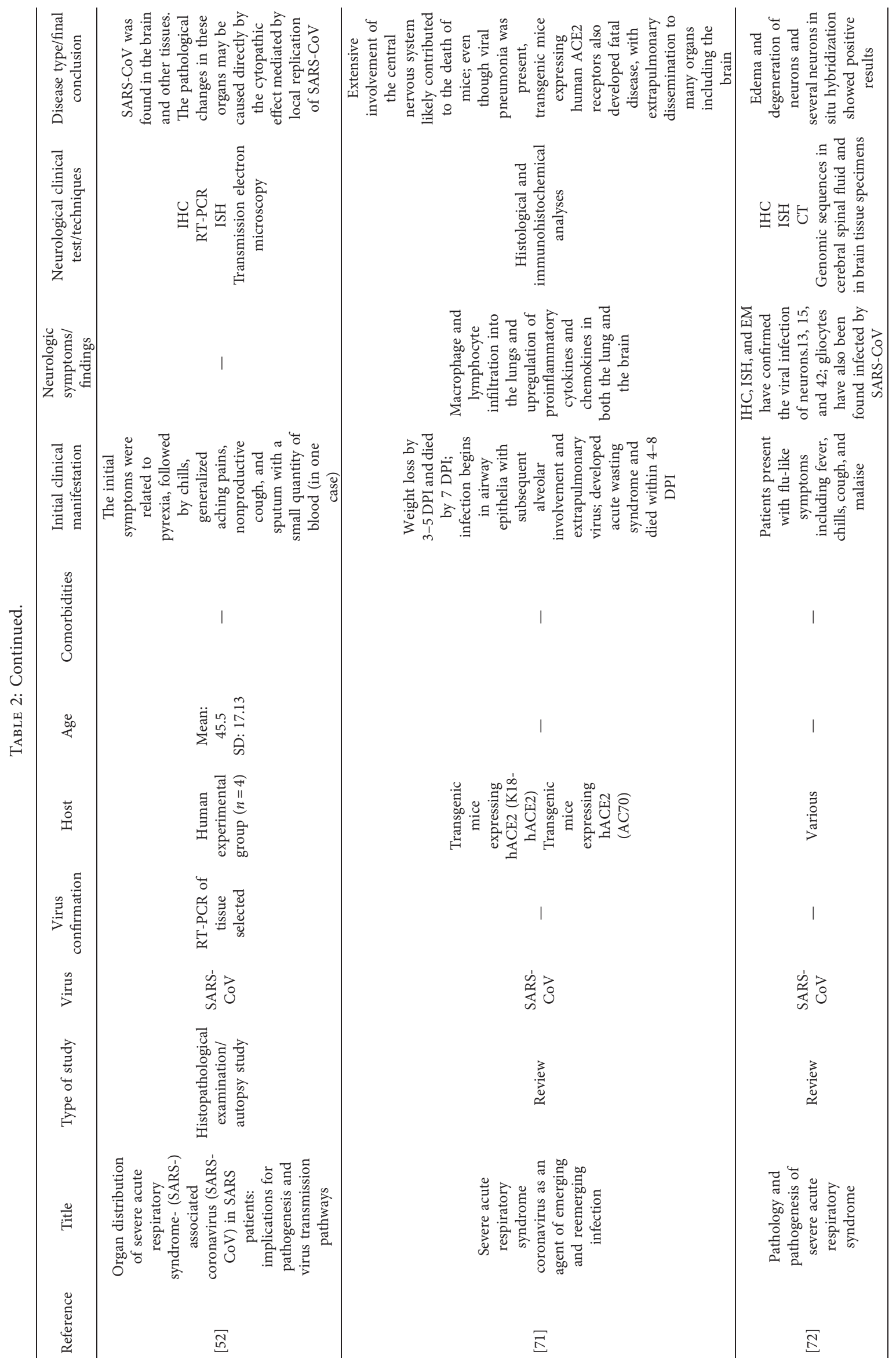




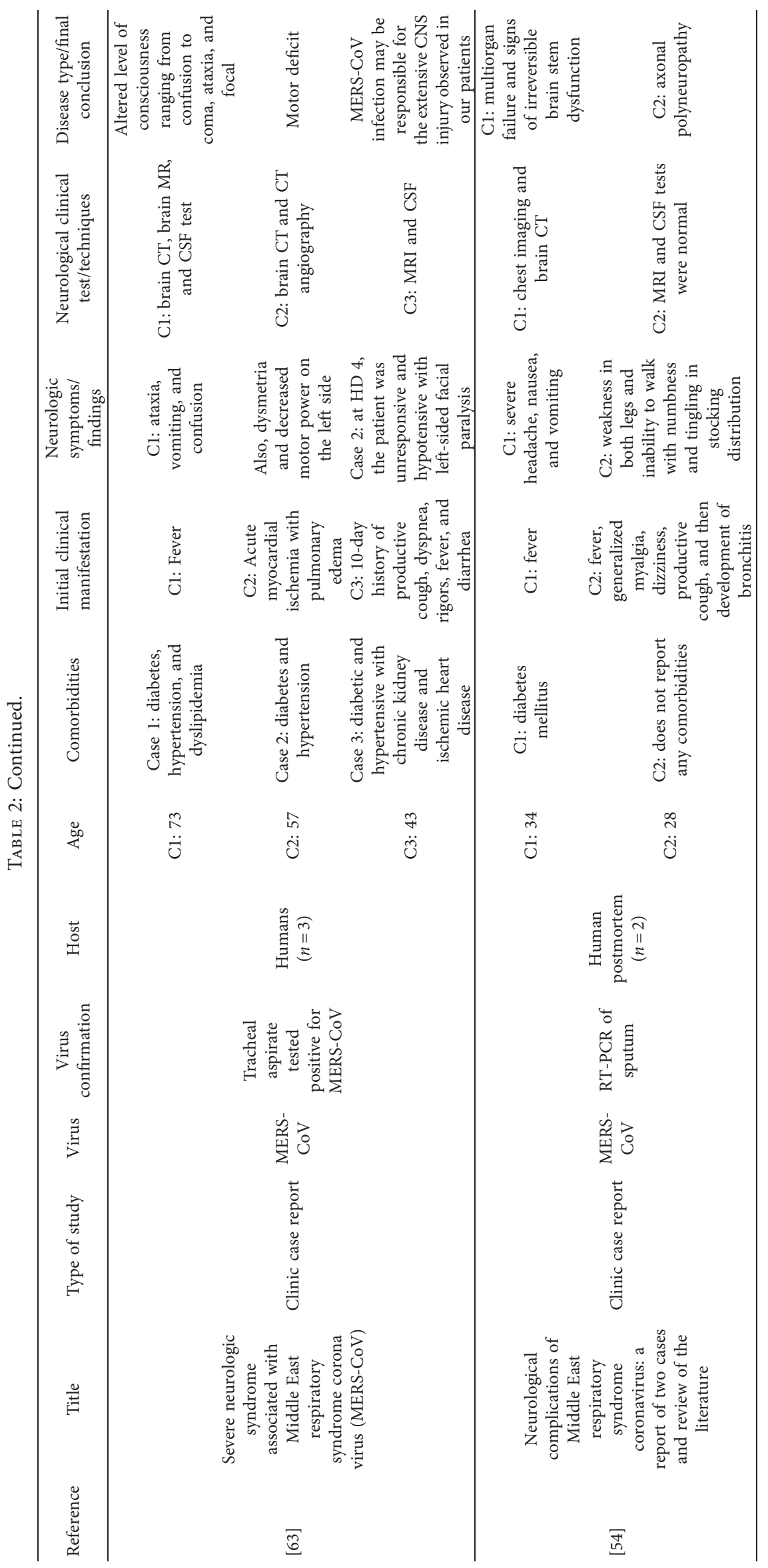




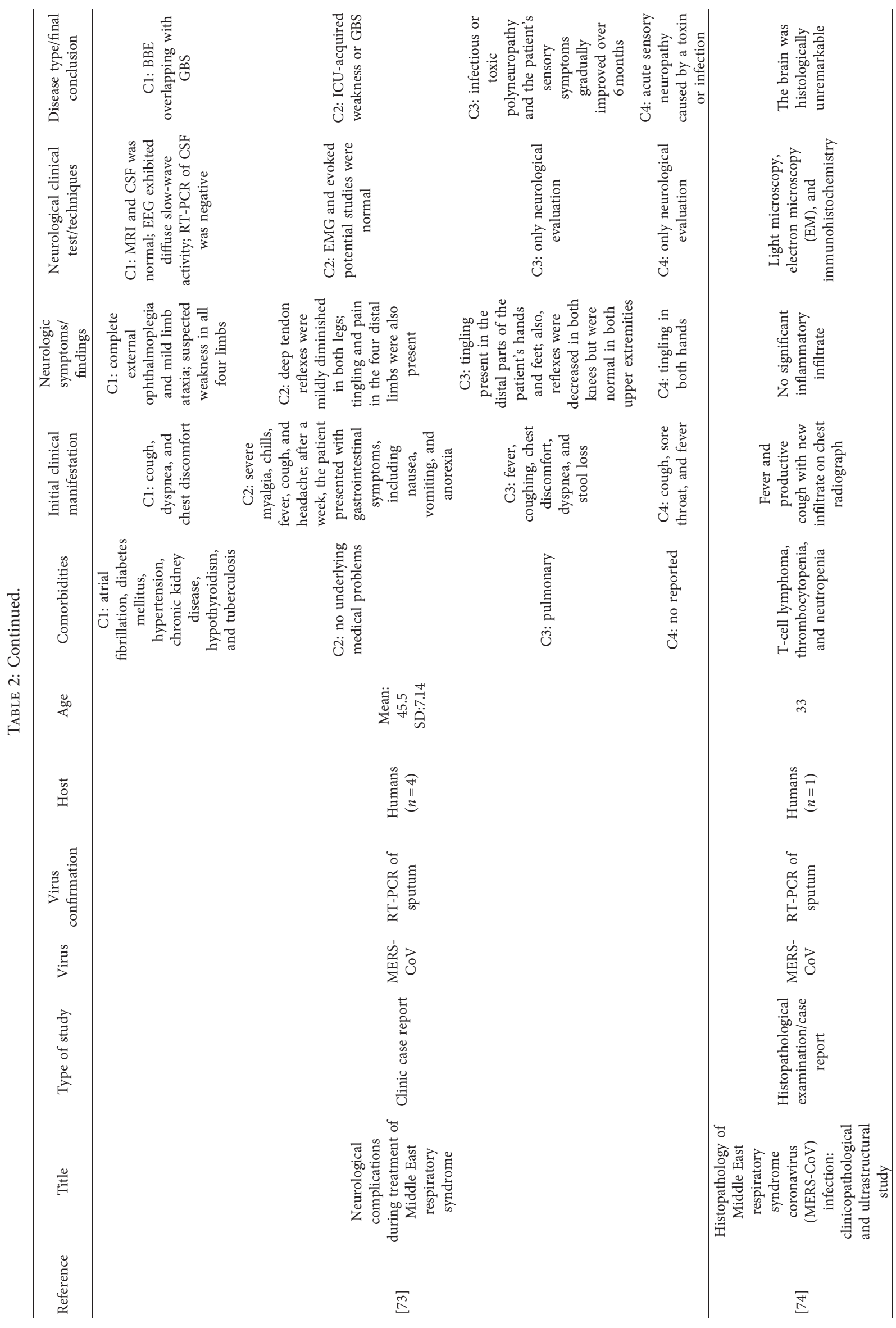




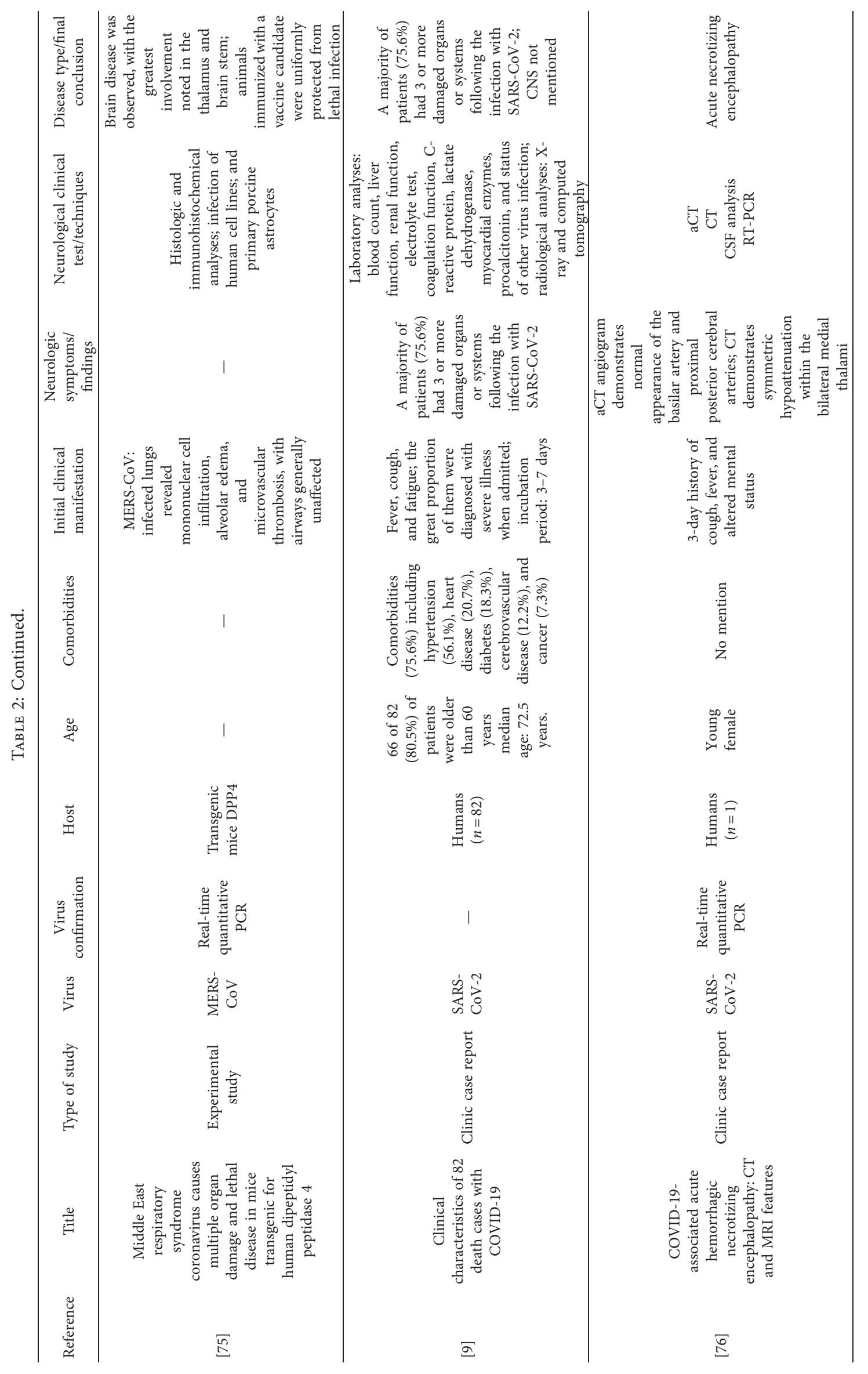




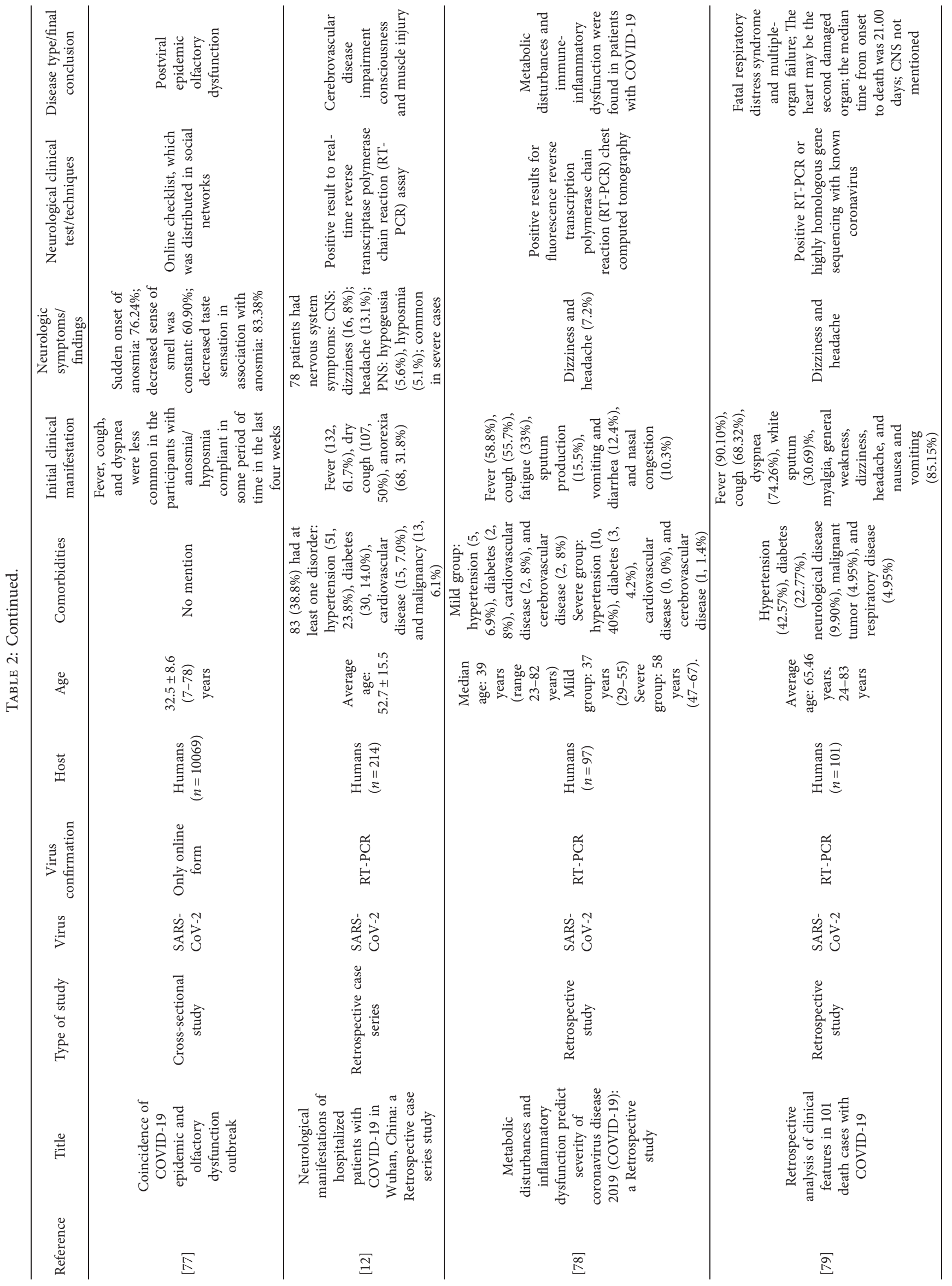




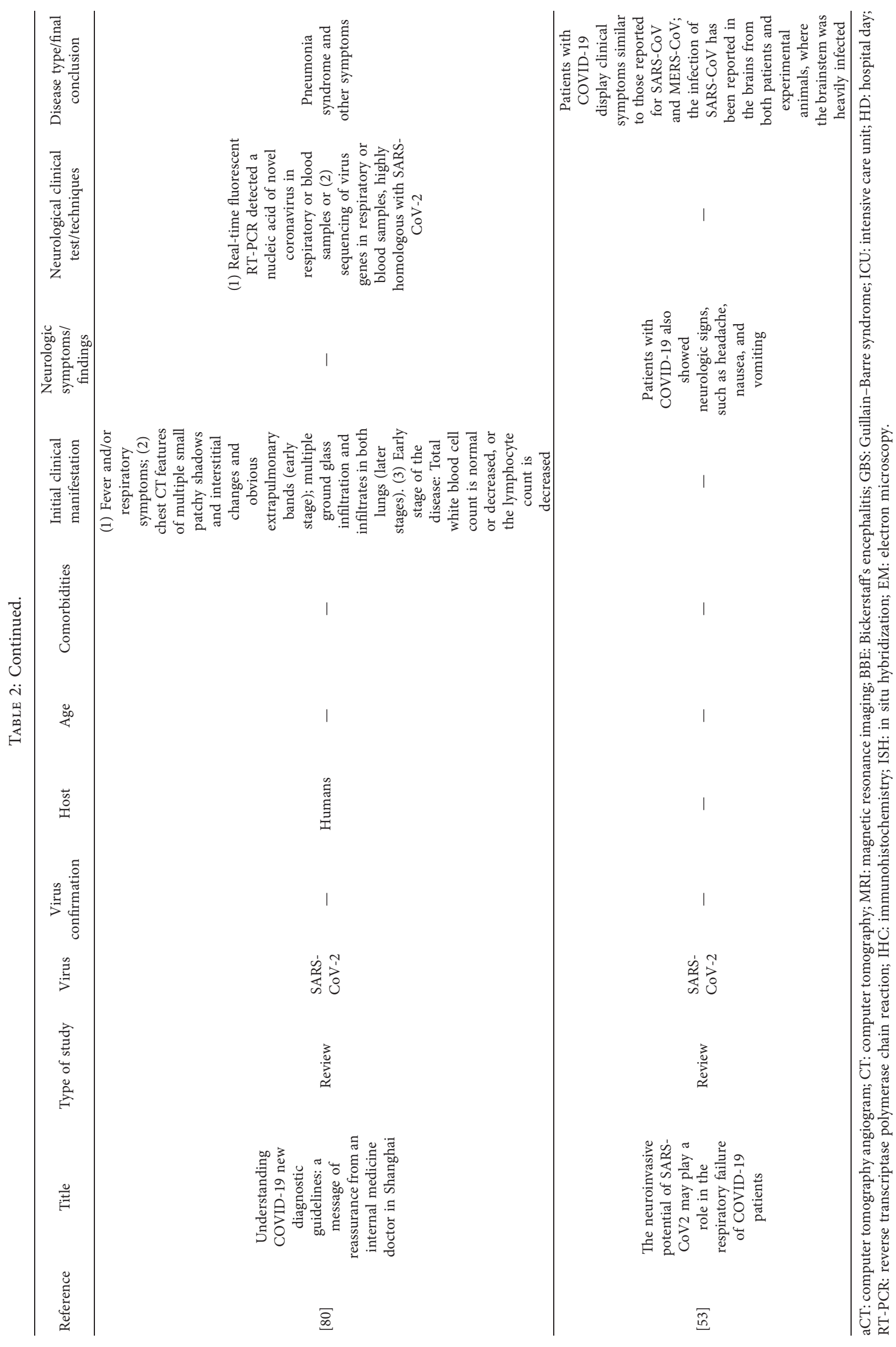




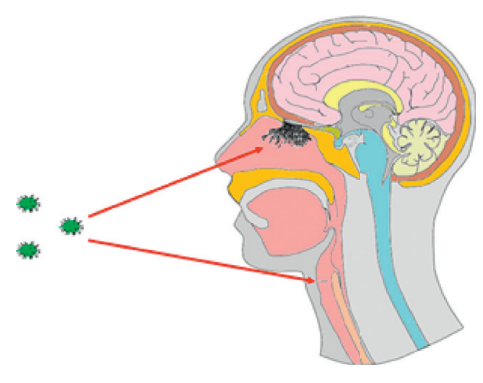

(a)

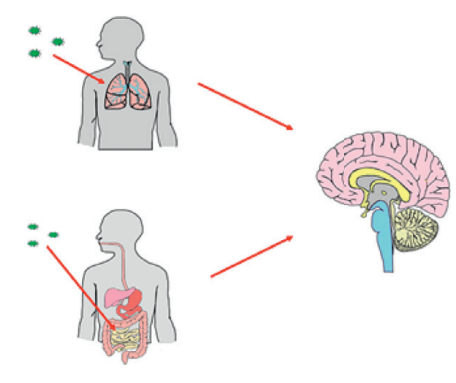

(b)

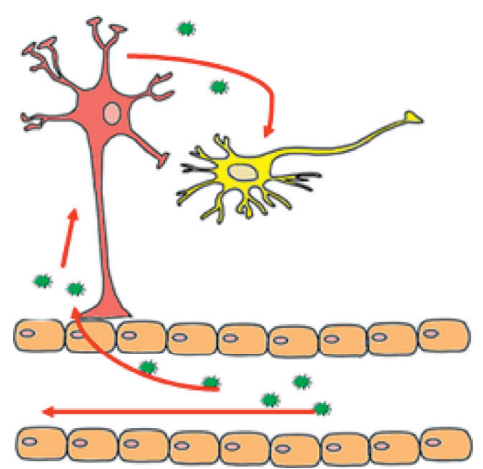

(c)

Figure 2: Possible mechanisms of brain infection. (a) The SARS-CoV-2 virus infects the nasal epithelium and throat. (b) Through infection of the lower respiratory tracts or enteric system, the viruses could use the homogenous or lymphatic route to reach the brain. (c) Rupture of BBB may cause glial cell infection as well as neuronal infection.

place involving the mechanisms of infection, transmission, etc. The appearance of epidemics by novel viruses of the same family displays the coronavirus as a fast-evolving virus [7] and particularly important for the investigation of its extensive contagious properties, its spread in several countries, morbidity and mortality.

Similar to other viruses, the SARS-CoV-2 virus spread rapidly through human-to-human transmission. Insufficient awareness of infection control in hospitals and international air travels facilitated the rapid global spread [71]. Today, more than 200 countries around the world have reported patients with COVID-19, and there have been more than 25 000 deaths. Although there are a high number of recovered patients, no follow-up studies on the nonrespiratory symptoms have been reported. In this paper, we focus on the symptoms and infections of the central nervous system caused by coronaviruses (SARS-CoV, MERS-CoV, and SARS-CoV-2).

The incubation period of COVID-19 is from 2 to 14 days $[8,14]$. Different reports mention several symptoms, including fever, cough, and fatigue assumed as the most common symptoms [80]. In addition to these aforementioned signs, acute respiratory distress syndrome, shock, acute cardiac injury, and acute kidney injury are reported, with $20 \%$ to $30 \%$ of cases developing serious illness [78].

Previous studies demonstrated that coronaviruses contain neuroinvasive, neurotropic, and neurovirulent properties regardless of the pulmonary infection, as it has been shown in some cases. The presence of SARS-CoV and MERS-CoV viruses was usually confirmed by RT-PCR, immunohistochemistry, and in situ hybridization in postmortem studies [52]. Other clinical approaches may include CT, MRI, and cerebrospinal fluid (CSF) test, to check SARS$\mathrm{CoV}-2$ by reverse transcriptase polymerase chain reaction. Analysis of the data suggests that a significant percentage of patients infected with COVID-19 may have neurological complications that may last longer than the lung infection itself. Initial neurological symptoms are diverse and include deterioration of mental status, confusion or coma, dizziness, headache, nausea and vomiting, anosmia/hyposmia, dysgeusia/hypogeusia, and seizures.
Further studies are urged to be performed to distinguish between opportunistic and disease-associated viral presence in the human brain [25] and also to describe the key mediator mechanism in brain damage induced by SARS-CoV-2 infection.

There have been some suggested mechanisms through which this virus affects the central nervous system, pointing to neuroinvasive characteristics similar to other human coronaviruses [31]. Because the exact mechanism is not thoroughly understood, autopsy studies are needed to further understand the mechanism [54]. It is possible that the neuroinvasive potential includes different routes such us hematogenous, lymphatic routes, olfactory tract [46], and optic nerve. Therefore, the advent of neurological symptoms should be monitored and analyzed more intensively. Surveillance should be maintained promptly, identifying other nonrespiratory symptoms, along with the follow-up of recovered patients and asymptomatic COVID-19-positive individuals [83].

The incubation period may vary for the infection of the lungs and other tissues, depending on the viral niche accumulation. A confirmative test is always recommended in the respiratory tract and CSF if a patient presents neurologic symptoms. Those are important to exploit the knowledge of neuroinvasion and dissemination of other similar coronaviruses to increase the ability to control the viral infection, detection of symptoms, and research focus on the possible mechanisms of neuropathogenesis.

The recent appearance and discovery of COVID-19, in addition to the ease of its transmission, has made SARSCOV-2 a virus with a great impact on the public health worldwide. The profiling of the condition and the understanding of the affected organs, in particular the central nervous system whose condition could have sequelae over time, are of vital importance. Therefore, the establishment of an adequate profile of the disease will also favor the adoption of health measures.

3.1. Limitations. This study has potential limitations. First, a few reported cases of neurological symptoms caused by COVID-19, observations of the process, and prognosis of the 
neurologic disease are needed. Second, this paper mainly uses the descriptive analysis to review and summarize the clinical cases.

\section{Conclusion}

Recent findings in COVID-19 are closely related to those reported in SARS and MERS. Specifically, here, we review those related with the neurologic syndromes. The structural homology and nucleotide identity are higher than $51 \%$ in MERS and $79 \%$ in SARS [25]. In both epidemics cases, reports regarding neurologic syndrome were investigated.

To our concern, there have been no follow-up studies related to the CNS. Now, with the global pandemic, COVID19 , case reports suggest similar CNS infection by the SARSCoV-2 opportunistic virus [92]. Coronaviruses are a rapidly evolving virus that can disrupt the human life, infect many organs such as the CNS, and probably leave different niches of infection that can generate a variety of clinical symptoms from typical cough, fever, and pneumonia infection to a more complex presentation that includes neurological syndromes. Consequently, further studies are necessary to elucidate if this neurological syndrome is reversible or if it may refer to possible disabilities or if it may even promote other brain pathologies that may include encephalitis, multiple sclerosis, or others.

\section{Appendix}

\section{A. Criteria}

(1) English language

(2) Peer-reviewed journals and journals indexed in the Journal Citation Reports (JCR)

(3) Published since January 2000

(4) Empirical studies, systematic reviews, meta-analyses, clinical practice guidelines, or case report

(5) Human participants

(6) Words: "coronavirus" or "SARS-CoV" or "MERS" or "COVID-19" or "SARS-CoV-2" and "neurological syndrome" or "central nervous system" or "brain" or "brain infection" or "neurological disorder"

(7) Clinical studies, case reports, journal articles, and systematic reviews

(8) Issues: neurosciences neurology, psychiatry, behavioral sciences, or psychology

\section{B. PubMed Search Words}

"Coronavirus" OR "SARS-CoV” OR "MERS” OR “COVID19" OR "SARS-CoV-2") ANDand "neurological syndrome" OR "central nervous system" OR "brain" OR "brain infection" OR "neurological disorder."

\section{Scopus Search Words}

TITLE-ABS-KEY ("coronavirus" OR "SARS-CoV” OR “MERS” OR “COVID-19” OR “SARS-CoV-2”) AND TITLE-
ABS-KEY ("neurological syndrome" OR "central nervous system" OR "brain” OR "brain infection" OR "neurological disorder") AND (LIMIT-TO ( LANGUAGE, "English”) ) AND (LIMIT-TO ( EXACTKEYWORD, "Human") OR LIMIT-TO (EXACTKEYWORD, "Humans").

\section{Web of Science Search Words}

Filters: English/2000/article, review, case report, and clinical trial.

Note: it does not allow putting Human as filter.

(TS = "coronavirus" OR TS = "SARS-CoV" OR TS = "MERS" OR TS = "COVID-19" OR TS = "SARS-CoV2") AND (TS = "neurological syndrome" OR TS = "central nervous system" OR TS = " brain" OR TS = "brain infection" OR TS = "neurological disorder") AND (TS = "human" OR TS = "humans")

\section{E. Types of Documents}

Articles or reviews or case reports.

\section{F. Research Area}

Neurosciences, Neurology, and Psychiatry or Behavioral Sciences or Psychology.

Period: From 2000: WOS, BCI, BIOSIS, CCC, DIIDW, KJD, MEDLINE, RSCI, and SCIELO.

Language $=$ auto.

\section{Conflicts of Interest}

The authors declare that there are no conflicts of interest.

\section{Authors' Contributions}

Zegarra-Valdivia conceptualized the study; Zegarra-Valdivia and Chino-Vilca were involved in the methodology; Zegarra-Valdivia, Chino-Vilca, and Tairo-Cerron were responsible for the writing and preparation of the original draft; Zegarra-Valdivia, Chino-Vilca, Tairo-Cerron, Munive, Lastarria-Perez, and Ames-Guerrero contributed in writing, review, and editing. All authors have read and agreed to the final submitted version of the manuscript for publications.

\section{Acknowledgments}

We greatly appreciate the comments of all the experts who gave insight into this paper and all the professionals fighting this pandemic. J. A. Zegarra-Valdivia and B. N. Chino acknowledge the financial support from the National Council of Science, Technology, and Technological Innovation (CONCYTEC, Perú) through the National Fund for Scientific and Technological Development (FONDECYT, Perú).

\section{References}

[1] J. F. Bale, "Emerging viral infections," Seminars in Pediatric Neurology, vol. 19, no. 3, pp. 152-157, 2012. 
[2] J. W. LeDuc and A. Barry, "SARS: the first pandemic of the 21st century," Emerging Infectious Diseases, vol. 11, pp. 1-2, 2004.

[3] Nuevo coronavirus 20192020.

[4] L. Van der hoek, "Human coronaviruses: what do they cause ?" International Society of Antiviral Research, vol. 36, 2007.

[5] M. A. Shereen, S. Khan, A. Kazmi, N. Bashir, and R. Siddique, "COVID-19 infection: origin, transmission, and characteristics of human coronaviruses," Journal of Advertising Research, vol. 67, 2020.

[6] A. M. Zaki, S. van Boheemen, T. M. Bestebroer, A. D. M. E. Osterhaus, and R. A. M. Fouchier, "Isolation of a novel coronavirus from a man with pneumonia in Saudi Arabia," New England Journal of Medicine, vol. 367, no. 19, pp. 1814-1820, 2012.

[7] P. K. S. Chan and M. C. W. Chan, "Tracing the SARScoronavirus," Journal of Thoracic Disease, vol. 5, no. 2, pp. S118-S121, 2013.

[8] D. Wang, M. Zhou, X. Nie et al., "Epidemiological characteristics and transmission model of corona virus disease 2019 in China," Journal of Thoracic Disease, vol. 1, pp. 1-6, 2020.

[9] B. Zhang, X. Zhou, Y. Qiu et al., "Clinical characteristics of 82 death cases with COVID-19," medRxiv, vol. 5, 2020.

[10] Y. Huang, H. Zhou, R. Yang, Y. Xu, X. Feng, and P. Gong, "Clinical characteristics of 36 non-survivors with COVID-19 in Wuhan, China," medRxiv, vol. 5, 2020.

[11] D. Wu, T. Wu, Q. Liu, and Z. Yang, "The SARS-CoV-2 outbreak: what we know," Journal of Thoracic Disease, vol. 5, 2020.

[12] L. Mao, M. Wang, S. Chen et al., "Neurological manifestations of hospitalized patients with COVID-19 in wuhan, China: a retrospective case series study," medRxiv, vol. 5, 2020.

[13] P. Xu, G.-D. Sun, and Z.-Z. Li, "Clinical characteristics of two human to human transmitted coronaviruses: corona virus disease 2019 versus middle east respiratory syndrome coronavirus," medRxiv, vol. 5, 2020.

[14] S. Keyhan, H. Fallahi, and B. Cheshmi, "Dysosmia and dysgeusia due to the 2019 novel coronavirus; a hypothesis that needs further investigation Itextbar maxillofacial plastic and reconstructive surgery \textbar full text," 2020.

[15] S. Keyhan, "Novel coronavirus 2019-nCoV: prevalence, biological and clinical characteristics comparison with SARSCoV and MERS-CoV," 2020.

[16] M. Desforges, A. Le Coupanec, P. Dubeau et al., "Human coronaviruses and other respiratory viruses: underestimated opportunistic pathogens of the central nervous system?" Viruses-Basel, vol. 12, p. 14, 2020.

[17] S. R. Weiss and J. L. Leibowitz, "Chapter 4 - coronavirus pathogenesis," in Advances in Virus Research, K. Maramorosch, A. J. Shatkin, and F. A. Murphy, Eds., Vol. 81, Academic Press, Berlin, Germany, 2011.

[18] P. E. Pellett, S. Mitra, and T. C. Holland, "Basics of virology," Neurovirology, vol. 123, pp. 45-66, 2014.

[19] Y. Li, H. Li, R. Fan et al., "Coronavirus infections in the central nervous system and respiratory tract show distinct features in hospitalized children," Intervirology, vol. 59, no. 3, pp. 163$169,2016$.

[20] J. K. Stodola, G. Dubois, A. Le Coupanec, M. Desforges, and P. J. Talbot, "The OC43 human coronavirus envelope protein is critical for infectious virus production and propagation in neuronal cells and is a determinant of neurovirulence and CNS pathology," Virology, vol. 515, pp. 134-149, 2018.

[21] Y. Matoba, C. Abiko, T. Ikeda et al., "Detection of the human coronavirus 229E, HKU1, NL63, and OC43 between 2010 and
2013 in Yamagata, Japan,” Japanese Journal of Infectious Diseases, vol. 68, no. 2, pp. 138-141, 2015.

[22] E. R. Gaunt, A. Hardie, E. C. J. Claas, P. Simmonds, and K. E. Templeton, "Epidemiology and clinical presentations of the four human coronaviruses 229E, HKU1, NL63, and OC43 detected over 3 years using a novel multiplex real-time PCR method," Journal of Clinical Microbiology, vol. 48, no. 8, pp. 2940-2947, 2010.

[23] T. K. Cabeça and N. Bellei, "Human coronavirus NL-63 infection in a Brazilian patient suspected of H1N1 2009 influenza infection: description of a fatal case," Journal of Clinical Virology, vol. 53, no. 1, pp. 82-84, 2012.

[24] E. A. Yeh, A. Collins, M. E. Cohen, P. K. Duffner, and H. Faden, "Detection of coronavirus in the central nervous system of a child with acute disseminated encephalomyelitis," Pediatrics, vol. 113, no. 1, pp. E73-E76, 2004.

[25] M. Desforges, T. C. Miletti, M. Gagnon, and P. J. Talbot, "Activation of human monocytes after infection by human coronavirus 229E," Virus Research, vol. 130, no. 1-2, pp. 228-240, 2007.

[26] S. P. Adhikari, S. Meng, Y. Wu et al., "A literature review of 2019 novel coronavirus during the early outbreak period: epidemiology, causes, clinical manifestation and diagnosis, prevention and control," 2020.

[27] P. Sampathkumar, Z. Temesgen, T. F. Smith, and R. L. Thompson, "SARS: epidemiology, clinical presentation, management, and infection control measures," Mayo Clinic Proceedings, vol. 78, no. 7, pp. 882-890, 2003.

[28] D. S. C. Hui, M. C. H. Chan, A. K. Wu, and P. C. Ng, "Severe acute respiratory syndrome (SARS): epidemiology and clinical features," Postgraduate Medical Journal, vol. 80, no. 945, pp. 373-381, 2004.

[29] M. S. Nassar, M. A. Bakhrebah, S. A. Meo, M. S. Alsuabeyl, and W. A. Zaher, "Middle East Respiratory Syndrome Coronavirus (MERS-CoV) infection: epidemiology, pathogenesis and clinical characteristics," European Review for Medical and Pharmacological Sciences, vol. 22, no. 15, pp. 4956-4961, 2018.

[30] V. Paraluppi, M. C. Pintus, V. Fanos, and M. A. Marcialis, "COVID-19 in newborns and in children: the state of the art," Journal of Pediatric and Neonatal Individualized Medicine n.D, vol. 9, pp. 1-13, 2014.

[31] M. Desforges, A. Le Coupanec, J. K. Stodola, M. MeessenPinard, and P. J. Talbot, "Human coronaviruses: viral and cellular factors involved in neuroinvasiveness and neuropathogenesis," Virus Research, vol. 194, pp. 145-158, 2014.

[32] S. Navas-Martin and S. R. Weiss, "SARS: lessons learned from other coronaviruses," Viral Immunology, vol. 16, no. 4, pp. 461-474, 2003.

[33] I. Ghinai, T. D. McPherson, J. C. Hunter et al., "First known person-to-person transmission of severe acute respiratory syndrome coronavirus 2 (SARS-CoV-2) in the USA," Lancet, vol. 0, pp. 1-8, 2020.

[34] I. Y. J. Seah, D. E. Anderson, A. E. Z. Kang et al., “Assessing viral shedding and infectivity of tears in coronavirus disease 2019 (COVID-19) patients,” Ophthalmology, vol. 581, 2020.

[35] H. Algahtani, B. Shirah, W. Bassuni, and R. Adas, "Bilateral numb chin syndrome as the initial presentation of Burkitt's lymphoma/leukemia: a report of two cases and review of the literature," Case Reports in Hematology, vol. 2016, pp. 1-7, 2016.

[36] D. Skinner, B. S. Marro, and T. E. Lane, "Chemokine CXCL10 and coronavirus-induced neurologic disease," Viral Immunology, vol. 32, no. 1, pp. 25-37, 2019. 
[37] S. A. Stohlman and D. R. Hinton, "Viral induced demyelination," Brain Pathology (Zurich, Switzerland), vol. 11, no. 1, pp. 92-106, 2001.

[38] N. Arbour, R. Day, J. Newcombe, and P. J. Talbot, "Neuroinvasion by human respiratory coronaviruses," Journal of Virology, vol. 74, no. 19, pp. 8913-8921, 2000.

[39] W. G. Glass and T. E. Lane, "Functional analysis of the CC chemokine receptor 5 (CCR5) on virus-specific CD8+ T cells following coronavirus infection of the central nervous system," Virology, vol. 312, no. 2, pp. 407-414, 2003.

[40] H. J. Maier, B. W. Neuman, E. Bickerton et al., "Extensive coronavirus-induced membrane rearrangements are not a determinant of pathogenicity," Scientific Reports, vol. 6, 2016.

[41] J. Xu, S. Zhong, J. Liu et al., "Detection of severe acute respiratory syndrome coronavirus in the brain: potential role of the chemokine mig in pathogenesis," Clinical Infectious Diseases, vol. 41, no. 8, pp. 1089-1096, 2005.

[42] N. Karimi, A. Sharifi, and N. Rouhani, "Frequent convulsive seizures in an adult patient with COVID-19: a case report," Iranian Red Crescent Medical Journal, vol. 22, pp. 1-3, 2014.

[43] Y. M. Arabi, A. Harthi, J. Hussein et al., "Severe neurologic syndrome associated with Middle East respiratory syndrome corona virus (MERS-CoV)," Infection, vol. 43, no. 4, pp. 495-501, 2015.

[44] H. Zhou, J. Zhao, and S. Perlman, "Autocrine interferon priming in macrophages but not dendritic cells results in enhanced cytokine and chemokine production after coronavirus infection," MBio, vol. 1, no. 4, pp. e00219-10, 2010.

[45] J. Zhou, H. Chu, J. F.-W. Chan, and K.-Y. Yuen, "Middle East respiratory syndrome coronavirus infection: virus-host cell interactions and implications on pathogenesis," Virology Journal, vol. 12, p. 218, 2015.

[46] J. Cui, F. Li, and Z.-L. Shi, "Origin and evolution of pathogenic coronaviruses," Nature Reviews Microbiology, vol. 17, no. 3, pp. 181-192, 2019.

[47] A. M. Baig, A. Khaleeq, U. Ali, and H. Syeda, "Evidence of the COVID-19 virus targeting the CNS: tissue distribution, hostvirus interaction, and proposed neurotropic mechanisms," ACS Chemical Neuroscience, vol. 11, no. 7, pp. 995-998, 2020.

[48] J. R. St-Jean, M. Desforges, and P. J. Talbot, "Genetic evolution of human coronavirus OC43 in neural cell culture," Advances in Experimental Medicine and Biology, vol. 581, pp. 499-502, 2006.

[49] M. Desforges, A. Le Coupanec, É. Brison, M. Meessen-Pinard, and P. J. Talbot, "Neuroinvasive and neurotropic human respiratory coronaviruses: potential neurovirulent agents in humans," Advances in Experimental Medicine and Biology, vol. 807, pp. 75-96, 2014.

[50] D. J. Favreau, M. Meessen-Pinard, M. Desforges, and P. J. Talbot, "Human coronavirus-induced neuronal programmed cell death is cyclophilin D dependent and potentially caspase dispensable," Journal of Virology, vol. 86, no. 1, pp. 81-93, 2012.

[51] Q.-L. Zhang, Y.-Q. Ding, J.-L. Hou et al., "Detection of severe acute respiratory syndrome (SARS)-associated coronavirus RNA in autopsy tissues with in situ hybridization," Di Yi Jun Yi Da Xue Xue Bao, vol. 23, pp. 1125-1127, 2003.

[52] Y. Ding, L. He, Q. Zhang et al., "Organ distribution of severe acute respiratory syndrome (SARS) associated coronavirus(SARS-CoV) in SARS patients: implications for pathogenesis and virus transmission pathways," The Journal of Pathology, vol. 203, no. 2, pp. 622-630, 2004.

[53] Y.-C. Li, W.-Z. Bai, and T. Hashikawa, "The neuroinvasive potential of SARS-CoV2 may play a role in the respiratory failure of COVID-19 patients," The Journal of Pathology, vol. 581, 2020.

[54] P. Simmonds and P. Aiewsakun, "Virus classification-where do you draw the line?" Archives of Virology, vol. 163, no. 8, pp. 2037-2046, 2018.

[55] Y.-R. Guo, Q.-D. Cao, Z.-S. Hong et al., "The origin, transmission and clinical therapies on coronavirus disease 2019 (COVID-19) outbreak - an update on the status," Military Medical Research, vol. 7, p. 11, 2020.

[56] B. L. Haagmans and A. D. M. E. Osterhaus, "Coronaviruses and their therapy," Antiviral Research, vol. 71, no. 2-3, pp. 397-403, 2006.

[57] R. Lu, X. Zhao, J. Li et al., "Genomic characterisation and epidemiology of 2019 novel coronavirus: implications for virus origins and receptor binding," The Lancet, vol. 395, no. 10224, pp. 565-574, 2020.

[58] N. Yoshikawa, T. Yoshikawa, T. Hill et al., "Differential virological and immunological outcome of severe acute respiratory syndrome coronavirus infection in susceptible and resistant transgenic mice expressing human angiotensinconverting enzyme 2," Journal of Virology, vol. 83, no. 11, pp. 5451-5465, 2009.

[59] A. R. Fehr and S. Perlman, "Coronaviruses: an overview of their replication and pathogenesis," Coronaviruses, vol. 1282, pp. 1-23, 2015.

[60] H. J. Maier, E. Bickerton, and P. Britton, "Coronaviruses. Methods and Protocols," 2020.

[61] N. C. Peeri, N. Shrestha, M. S. Rahman et al., "The SARS, MERS and novel coronavirus (COVID-19) epidemics, the newest and biggest global health threats: what lessons have we learned?" International Journal of Epidemiology, vol. 12, 2020.

[62] J. Liu, X. Zheng, Q. Tong et al., "Overlapping and discrete aspects of the pathology and pathogenesis of the emerging human pathogenic coronaviruses SARS-CoV, MERS-CoV, and 2019-nCoV," Journal of Medical Virology, vol. 92, no. 5, pp. 491-494, 2020.

[63] X. Li, M. Geng, Y. Peng, L. Meng, and S. Lu, "Molecular immune pathogenesis and diagnosis of COVID-19," Journal of Pharmaceutical and Biomedical Analysis, vol. 92, 2020.

[64] C. Liu, Q. Zhou, Y. Li et al., "Research and development on therapeutic agents and vaccines for COVID-19 and related human coronavirus diseases," ACS Central Science, vol. 92, 2020.

[65] J. Netland, D. K. Meyerholz, S. Moore, M. Cassell, and S. Perlman, "Severe acute respiratory syndrome coronavirus infection causes neuronal death in the absence of encephalitis in mice transgenic for human ACE2," Journal of Virology, vol. 82, no. 15, pp. 7264-7275, 2008.

[66] S. Perlman and A. A. Dandekar, "Immunopathogenesis of coronavirus infections: implications for SARS," Nature Reviews. Immunology, vol. 5, no. 12, pp. 917-927, 2005.

[67] Y. Mao, W. Lin, J. Wen, and G. Chen, "Clinical and pathological characteristics of 2019 novel coronavirus disease ( COVID-19 ): a systematic reviews," Emerging Infectious Diseases, vol. 5, pp. 1-31, 2020.

[68] M. Yamashita, M. Yamate, G.-M. Li, and K. Ikuta, "Susceptibility of human and rat neural cell lines to infection by SARS-coronavirus," Biochemical and Biophysical Research Communications, vol. 334, no. 1, pp. 79-85, 2005.

[69] X. Jiang, S. Rayner, and M. H. Luo, "Does SARS-CoV-2 has a longer incubation period than SARS and MERS?" Journal of Medical Virology, vol. 92, no. 5, pp. 476-478, 2020.

[70] K.-K. Lau, W.-C. Yu, C.-M. Chu, S.-T. Lau, B. Sheng, and K.-Y. Yuen, "Possible central nervous system infection by 
SARS coronavirus," Emerging Infectious Diseases, vol. 10, no. 2, pp. 342-344, 2004.

[71] V. C. C. Cheng, S. K. P. Lau, P. C. Y. Woo, and K. Y. Yuen, "Severe acute respiratory syndrome coronavirus as an agent of emerging and reemerging infection," Clinical Microbiology Reviews, vol. 20, no. 4, pp. 660-694, 2007.

[72] J. Gu and C. Korteweg, "Pathology and pathogenesis of severe acute respiratory syndrome," The American Journal of $\mathrm{Pa}$ thology, vol. 170, no. 4, pp. 1136-1147, 2007.

[73] J.-E. Kim, J.-H. Heo, H.-o. Kim et al., "Neurological complications during treatment of Middle East respiratory syndrome," Journal of Clinical Neurology, vol. 13, no. 3, pp. 227-233, 2017.

[74] K. O. Alsaad, A. H. Hajeer, M. Al Balwi et al., "Histopathology of Middle East respiratory syndrome coronovirus (MERS$\mathrm{CoV}$ ) infection-clinicopathological and ultrastructural study," Histopathology, vol. 72, no. 3, pp. 516-524, 2018.

[75] K. Li, C. Wohlford-Lenane, S. Perlman et al., "Middle East respiratory syndrome coronavirus causes multiple organ damage and lethal disease in mice transgenic for human dipeptidyl peptidase 4," Journal of Infectious Diseases, vol. 213, no. 5, pp. 712-722, 2016.

[76] N. Poyiadji, G. Shahin, D. Noujaim, M. Stone, S. Patel, and B. Griffith, "COVID-19-associated acute hemorrhagic necrotizing encephalopathy: CT and MRI features," Radiology, vol. 213, 2020.

[77] S. H. R. Bagheri, A. M. Asghari, M. Farhadi et al., "Coincidence of COVID-19 epidemic and olfactory dysfunction outbreak," Otolaryngology, vol. 213, 2020.

[78] S. Nie, X. Zhao, K. Zhao, Z. Zhang, Z. Zhang, and Z. Zhang, "Metabolic disturbances and inflammatory dysfunction predict severity of coronavirus disease 2019 (COVID-19): a retrospective study," Infectious Diseases (Except HIV/AIDS), vol. 213, 2020.

[79] J. Chen, H. Fan, L. Zhang et al., "Retrospective analysis of clinical features in 101 death cases with COVID-19," Intensive Care and Critical Care Medicine, vol. 213, 2020.

[80] E. Bischof, G. Chen, and M. T. Ferretti, "Understanding COVID-19 new diagnostic guidelines-a message of reassurance from an internal medicine doctor in Shanghai," Swiss Medical Weekly, vol. 150, 2020.

[81] E. Brison, H. Jacomy, M. Desforges, and P. J. Talbot, "Glutamate excitotoxicity is involved in the induction of paralysis in mice after infection by a human coronavirus with a single point mutation in its spike protein," Journal of Virology, vol. 85, no. 23, pp. 12464-12473, 2011.

[82] A. Boucher, M. Desforges, P. Duquette, and P. J. Talbot, "Long-term human coronavirus-myelin cross-reactive T-cell clones derived from multiple sclerosis patients," Clinical Immunology, vol. 123, no. 3, pp. 258-267, 2007.

[83] A. Le Coupanec, M. Desforges, M. Meessen-Pinard et al., "Cleavage of a neuroinvasive human respiratory virus spike glycoprotein by proprotein convertases modulates neurovirulence and virus spread within the central nervous system," PLoS Pathog, vol. 11, 2015.

[84] C. Savarin and C. C. Bergmann, "Viral-induced suppression of self-reactive T cells: lessons from neurotropic coronavirusinduced demyelination," Journal of Neuroimmunology, vol. 308, pp. 12-16, 2017.

[85] M. Dubé, A. Le Coupanec, A. H. M. Wong, J. M. Rini, M. Desforges, and P. J. Talbot, "Axonal transport enables neuron-to-neuron propagation of human coronavirus OC43," Journal of Virology, vol. 92, no. 17, pp. 4-18, 2018.
[86] J. A. Edwards, F. Denis, and P. J. Talbot, "Activation of glial cells by human coronavirus OC43 infection," Journal of Neuroimmunology, vol. 108, no. 1-2, pp. 73-81, 2000.

[87] D. Anghelina, L. Pewe, and S. Perlman, "Pathogenic role for virus-specific CD4 T cells in mice with coronavirus-induced acute encephalitis," The American Journal of Pathology, vol. 169, no. 1, pp. 209-222, 2006.

[88] H. Jacomy, J. R. St-Jean, É. Brison, G. Marceau, M. Desforges, and P. J. Talbot, "Mutations in the spike glycoprotein of human coronavirus OC43 modulate disease in BALB/c mice from encephalitis to flaccid paralysis and demyelination," Journal of Neurovirology, vol. 16, no. 4, pp. 279-293, 2010.

[89] J. R. St-Jean, H. Jacomy, M. Desforges, A. Vabret, F. Freymuth, and P. J. Talbot, "Human respiratory coronavirus OC43: genetic stability and neuroinvasion," Journal of Virology, vol. 78, no. 16, pp. 8824-8834, 2004.

[90] N. Principi, S. Bosis, and S. Esposito, "Effects of coronavirus infections in children," Emerging Infectious Diseases, vol. 16, no. 2 , pp. $183-188,2010$.

[91] T. Tong, "Drug targets in severe acute respiratory syndrome (SARS) virus and other coronavirus infections," Infectious Disorders-Drug Targets, vol. 9, no. 2, pp. 223-245, 2009.

[92] M. P. Hosking and T. E. Lane, "The pathogenesis of murine coronavirus infection of the central nervous system," Critical Reviews in Immunology, vol. 30, no. 2, pp. 119-130, 2010. 